\title{
Enriquecimento proteico de resíduo de umbu-cajá empregando fermentação semissólida
}

\section{Protein enrichment of umbu-cajá residue using semisolid fermentation}

\author{
Jéssica Leite da Silva ${ }^{1 *}$, Osvaldo Soares da Silva ${ }^{2}$, Fernanda Maslova Soares Alves ${ }^{3}$, Neidemarques Casimiro Vieira ${ }^{4}$, \\ Ana Marinho do Nascimento 5
}

Resumo: Objetivou-se estudar o processo de enriquecimento proteico do bagaço do umbu-cajá com a utilização da levedura Saccharomyces cerevisiae, por meio de fermentação semissólida. O resíduo foi proveniente de uma fábrica de polpas localizada no município de Pombal, Paraíba a fermentação foi realizada em biorreatores de bandejas dispostos em estufa de circulação de ar a $37^{\circ} \mathrm{C}$ durante 72 horas. O maior teor de proteína bruta alcançado nos resíduos foi de 5,5\% às 48 horas de fermentação. O emprego da levedura (Saccharomyces cerevisiae) na fermentação semissólida do resíduo de umbu-cajá viabiliza a obtenção de um concentrado proteico, que poderá posteriormente ser utilizado como fonte alternativa de alto potencial proteico, em ração animal.

Palavras-chave: Proteína; Saccharomyces cerevisia; Aproveitamento.

Abstract: The objective of this study was to study the protein enrichment process of the umbu-cajá bagasse with the use of Saccharomyces cerevisiae yeast by means of semi-solid fermentation. The residue was from a pulp mill located in the Pombal municipality, Paraíba state. The fermentation was carried out in bioreactors of trays placed in an air circulation oven at $37{ }^{\circ} \mathrm{C}$ for 72 hours. The highest crude protein content in the residues was $5.5 \%$ at 48 hours of fermentation. The use of yeast (Saccharomyces cerevisiae) in the semi-solid fermentation of the ubu-cajá residue makes it possible to obtain a protein concentrate, which can later be used as an alternative source of high protein potential in animal ration.

Key words: Protein; Saccharomyces cerevisiae; Use.

\footnotetext{
Trabalho apresentado no III Simpósio de Ciências e Tecnologia (III SIMTAGRO), realizado entre 02 a 06 de outubro de 2017 no Centro de Ciências e Tecnologia Agroalimentar da Universidade Federal de Campina Grande, Pombal, Paraíba.

*Autor para correspondência

Recebido para publicação em 05/11/2017; aprovado em 23/11/2017

${ }^{1}$ Doutoranda em Engenharia de Processos, Universidade Federal de Campina Grande, Campus Campina Grande, Paraíba, e-mail: jessicaleite2010@ gmail.com ${ }^{2}$ Professor do Centro de Ciências e Tecnologia Agroalimentar, Universidade Federal de Campina Grande, Pombal, Paraíba, e-mail: osvaldo_so2002@yahoo.com.br

${ }^{3}$ Mestranda em Engenharia Química, Universidade Federal de Sergipe, Campus São Cristovão, Sergipe, e-mail: maslova@ hotmail.com

${ }^{4}$ Engenheiro de Alimentos, Universidade Federal de Campina Grande, Pombal, Paraíba, e-mail: neidemarquescasimiro@ hotmail.com

${ }^{5}$ Doutoranda em Engenharia de Processos, Universidade Federal de Campina Grande, Campus Campina Grande, Paraíba, e-mail: anamarinho06@hotmail.com
} 


\section{INTRODUÇÃO}

A produção de resíduos agroindustriais é inerente a qualquer setor produtivo. O Brasil vem se destacando como um dos países que mais produz resíduos agroindustriais, o que tem contribuído para o aumento da produção do lixo orgânico, provocando graves problemas ambientais. Estes resíduos poderiam ser utilizados, minimizando o desperdício de alimentos e gerando uma nova fonte alimentar (PINTO et al., 2005; SOUSA et al., 2011).

O processamento de umbu-cajá surge como uma alternativa viável de conservação, trazendo como vantagem a possibilidade de aproveitamento dos excedentes de produção, contornando problemas de sazonalidade e possibilitando sua distribuição por maiores períodos do ano (VIANA, 2008). No entanto, nesse processamento a geração de alta quantidade de resíduos, oriundo de cascas e sementes, que na maioria das vezes são descartados ao meio ambiente, já que, muitas vezes é escasso o conhecimento de técnicas de aproveitamento.

Os rejeitos agroindustriais podem ser reaproveitados através do processo de enriquecimento proteico, empregando microorganismos, por meio de fermentação semissólida. Esse processo apresenta vantagens quando comparada a técnica de fermentação submersa graças a seus aspectos físico-químicos, em especial a sua reduzida atividade de água, o que torna o processo mais produtivo com baixo investimento de capital e energia requerida (CAMPOS et al., 2003; MORAES, 2001).

A fermentação em estado sólido exerce um papel de destaque no aproveitamento de resíduos sólidos, já que, devido ao crescimento microbiano, ocorre a síntese de diversos compostos, onde muitos deles apresentam grande interesse para segmentos industriais, além de elevado valor agregado (PINTO et al., 2005).

No geral, a fermentação semissólida baseia-se no desenvolvimento microbiano na superfície de materiais sólidos, que apresentam a propriedade de absorver ou de conter água, com ou sem nutrientes solúveis. Na fermentação semissólida é essencial que os microorganismos desenvolvam-se com nutrientes difusíveis sobre a interface liquido- sólido (VINIEGRA-GONZALEZ, 1997).

As linhas de pesquisa em fermentação semissólida em geral são no enriquecimento proteico de resíduos agroindustriais (microorganismos selecionados elevam o conteúdo proteico desses materiais), a destoxificação de resíduos (eliminação de substâncias recalcitrantes que impedem sua aplicação intensiva) e a produção de compostos de alto valor agregado (enzimas e diferentes metabólitos) (RAIMBAULT, 1998; PANDEY, 2003).

O objetivo deste trabalho foi estudar o processo de enriquecimento proteico do bagaço do umbu-cajá com a utilização da levedura Saccharomyces cerevisiae, por meio de fermentação semissólida.

\section{MATERIAL E MÉTODOS}

O trabalho foi desenvolvido no Laboratório de Química, Bioquímica e Análises de Alimentos da Unidade Acadêmica de Tecnologia de Alimentos (UATA) na Universidade Federal de Campina Grande (UFCG).

O resíduo de umbu-cajá utilizado foi adquirido de uma fábrica de polpas localizada no sitio São João, município de Pombal/PB, foi realizada uma trituração do resíduo em moinho de facas, a fim de obter uma amostra mais homogênea.

Para determinar a quantidade de microorganismo utilizado no enriquecimento do resíduo, foi realizada a quantificação da umidade do resíduo em estufa a $105{ }^{\circ} \mathrm{C}$ até peso constante. $\mathrm{O}$ microorganismo utilizado para o enriquecimento do substrato em estudo foi a levedura Saccharomyces cerevisiae, desidratada com $1,3 \%$ de umidade, do tipo comercial fermento biológico, da marca Fleischmann.

A fermentação foi realizada nos biorreatores de bandejas, contendo 500 gramas dos resíduos, com quantidade de levedura adicionada de $2,0 \%$ a uma temperatura de $37{ }^{\circ} \mathrm{C}$ em estufa de circulação de ar forçado por um período de 72 horas, foram retiradas sete amostras nos tempos de $0,12,24$, 36, 48, 60 e 72 horas. Estudou-se a cinética do enriquecimento nutricional para observar o tempo adequado de fermentação dos resíduos.

Foram realizadas análises de proteína, sólidos solúveis e granulométrica, sendo o resíduo fermentado triturado em moinho de facas para utilização nas análises.

Para a determinação da proteína foi utilizado o método Kjeldahl, descrito pelo Instituto Adolfo Lutz (2008), os sólidos solúveis foram determinados por meio de refratômetro digital e a análise granulométrica foi realizada empregando peneiras de granulometria.

A preparação do resíduo, fermentação semissólida e trituração do material fermentado são apresentadas na Figura 1 .

Figura 1. Etapas da fermentação semissólida de resíduo de umbu-cajá. Pombal, Paraíba.

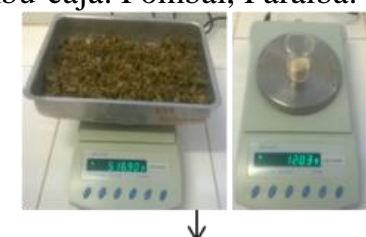

Pesagem do resíduo de umbu-cajá e da levedura Saccharomyces cerevisiae

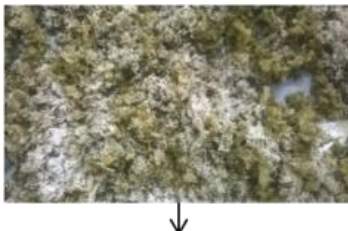

Homogeneização do resíduo de umbu-cajá com a levedura Saccharomyces cerevisiae

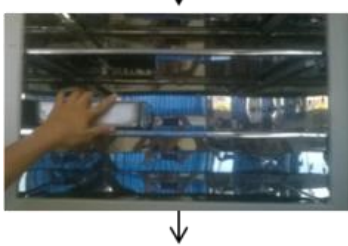

Fermentação do resíduo de umbu-cajá em estufa de circulação de ar a $37^{\circ} \mathrm{C}$

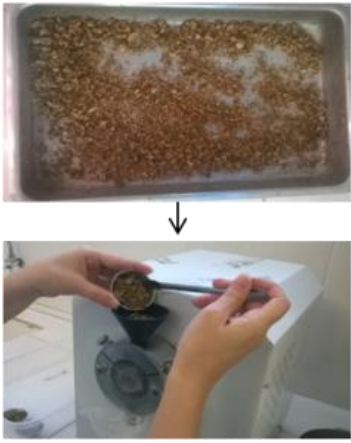

Material obtido após 72 horas de fermentação semissólida

Fonte: Autores (2017). 


\section{RESULTADOS E DISCUSSÃO}

Observa-se na Figura 2 o teor de proteína adquirido pelo resíduo de umbu-cajá após adição de levedura para fermentação semissólida numa temperatura de $37{ }^{\circ} \mathrm{C}$.

Percebe-se que o conteúdo proteico no resíduo de umbucajá fermentado aumentou gradativamente até as 48 horas em relação ao tempo de fermentação. No início do processo fermentativo foi constatado que o resíduo in natura tinha um teor proteico de $1,27 \%$, havendo aumento considerável às 48 horas, atingindo $5,5 \%$ e ao término da fermentação (72 horas) atingiu um teor de $4,65 \%$.

Figura 2. Teor proteico de resíduo de umbu-cajá em relação ao tempo de fermentação, com adição de $2,0 \%$ de levedura Saccharomyces cerevisiae.

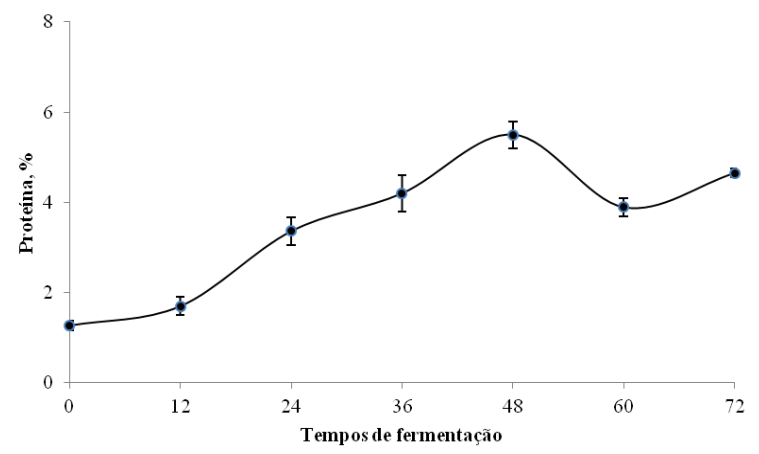

Santos et al. (2010) obteve teor de 20,71 $\pm 1,93 \%$ de proteína para resíduos do bagaço do pedúnculo do caju, utilizando $12 \%$ da concentração da levedura Saccharomyces cerevisiae e utilizando a temperatura de cultivo de $33{ }^{\circ} \mathrm{C}$ em estufa, Lousada Júnior et al. (2005), obteve após submissão ao processo de enriquecimento por desidratação os valores de proteínas no bagaço enriquecido de maracujá $(12,4 \%)$, acerola (10,5\%), e do melão (17,3\%). Assim os valores encontrados para o fruto do umbu-cajá foi inferior aos frutos analisados por esses dois autores, podendo ser atribuído ao emprego de diferentes concentrações de leveduras, diferentes métodos de enriquecimento e temperatura de processo diferenciada.

Na Figura 3 verifica-se os sólidos solúveis no resíduo de umbu-cajá durante o período de fermentação. O teor de sólidos solúveis no material enriquecido apresentou valores de $0,5-1,0 \%$, havendo redução durante o tempo de fermentação, de $0,9 \%$ no tempo 0 , para $0,5 \%$ no tempo de 72 horas (Figura 3).

Figura 3. Teor de sólidos solúveis de resíduo de umbu-cajá em relação ao tempo de fermentação, com adição de 2,0\% de levedura Saccharomyces cerevisiae.

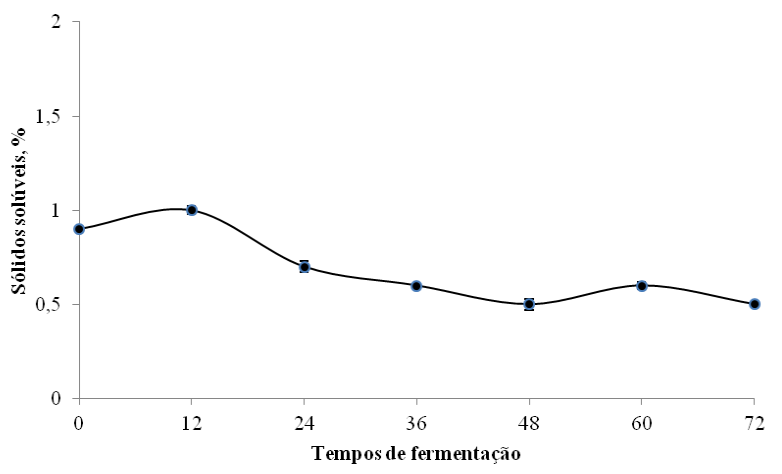

O decaimento nos valores de sólidos solúveis após o enriquecimento era previsto, já que o processo de fermentação semissólida utilizado prevê o uso dos açúcares (quantificados como sólidos solúveis) do meio para aumento proteico.

Verifica-se na Figura 4 a análise granulométrica do resíduo umbu-cajá após adição de levedura para fermentação numa temperatura de $37^{\circ} \mathrm{C}$ em um período de 72 horas. Em que pelo o aspecto do histograma, os resíduos não seguem uma distribuição normal, de modo que a distribuição dos resíduos apresenta diâmetro médio de $1 \mathrm{~mm}$, tendo em vista que $33 \%$ dos resíduos ficaram retidos na peneira de $1 \mathrm{~mm}$.

Figura 4. Análise granulométrica de resíduo de umbu-cajá em relação ao tempo de fermentação, com adição de 2,0\% de levedura Saccharomyces cerevisiae.

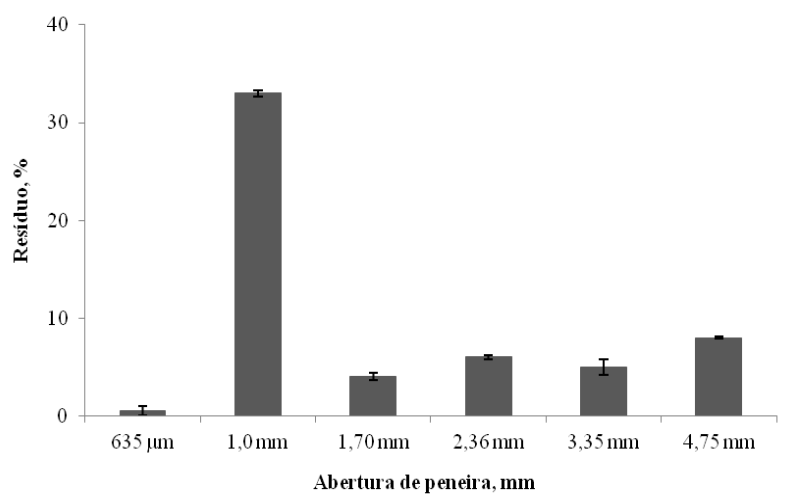

Autores como Alcântara et al., (2007); Alcântara et al., (2013); Souza et al., (2010), ressaltam a importância do tamanho das partículas dos resíduos, uma vez que os mesmos apresentam influência direta no processo fermentativo. Visto que, partículas maiores quando distribuídas no procedimento da fermentação semissólida, por obter maiores espaços interpartículas, podem vir a prejudicar os microorganismos na absorção de nutrientes. Enquanto partículas menores, apesar de oferecerem uma maior área superficial e grau de transformação ao ataque microbiano, dificultam a respiração e aeração do sistema, provocando dissipação de gases e calor produzido, além de prejudicar no rendimento do processo.

\section{CONCLUSÕES}

A fermentação semissólida do bagaço do fruto do umbucajá empregando a levedura Saccharomyces cerevisiae elevou o teor de proteína do resíduo em relação ao tempo, obtendo a maior concentração às 48 horas de fermentação. Demonstrando que essa técnica pode ser empregada com sucesso para enriquecimento proteico de resíduos de frutas, obtendo um concentrado proteico que poderá posteriormente ser utilizado como fonte alternativa de alto potencial proteico em ração animal.

\section{REFERÊNCIAS}

ALCÂNTARA, S. R.; ALMEIDA, F. A. C.; SILVA, F. L. H. Emprego do Bagaço Seco do pedúnculo do caju para posterior utilização em um processo de fermentação semissólida. Revista Brasileira de Produtos Agroindustriais, Campina Grande, v.9, n.2, p.137-142, 2007. 
AlCÂNTARA, S. R.; SOUSA, C. A. B.; ALMEIDA, F. A. C.; GOMES, J. P. Caracterização físico-química das farinhas do pedúnculo do caju e da casca do maracujá. Revista Brasileira de Produtos Agroindustriais, Campina Grande, v.15, n.4, p.349-355, 2013.

CAMPOS, A. R. N.; SANTANA, R. A. C.; DANTAS, J. P.; SILVA, F. L. H. Enriquecimento Proteico do bagaço do pedúnculo de caju (Anarcadium occidentale L.) por fermentação semi-sólida. Anais... XIV Simpósio Nacional de Fermentações, Florianópolis, Brasil, 2003.

INSTITUTO ADOLFO LUTZ. Normas Analíticas do Instituto Adolfo Lutz. v.1: Métodos químicos e físicos para análise de alimentos, 4. ed. São Paulo: IAL, 2008.

LOUSADA JUNIOR, J. E.; NEIVA, J. N. M.; RODRIGUEZ, N. M.; PIMENTEL, J. C. M.; LÔBO, R. N. B. Consumo e Digestibilidade de Subprodutos do Processamento de Frutas em Ovinos. Revista Brasileira de Zootecnia, v.34, n.2, p.659$669,2005$.

MORAES, I. O. Apostilha do curso de Fermentação SemiSólidana Obtenção de Bioprodutos. Embrapa, São Paulo, 2001.

PANDEY, A. Solid state fermentation. Biochemical Engineering Journal, v.13, n.2/3, p.81-84. 2003.

PINTO, G. A. S.; BRITO, E. S.; ANDRADE, A. M. R.; FRAGA, S. L. P.; TEIXEIRA, R., B. Fermentação em Estado Sólido: Uma Alternativa para o Aproveitamento e Valorização de Resíduos Agroindustriais Tropicais. Comunicado Técnico 102. Embrapa, Fortaleza, 2005.

RAIMBAULT, M. General and microbiological aspects of solid substrate fermentation. Eletronic Journal of Biotechnology, v.1, n.3, 1998.

SANTOS, R. C.; RIBEIRO FILHO, N. M.; ALSINA, O. L. S.; CONRADO, L. S. Enriquecimento Proteico de Bagaço do pseudofruto do Caju por via fermentativa. Anais... $1^{\circ}$ Congresso Químico do Brasil. João Pessoa - PB, 2010.

SOUSA, F. C.; SOUSA, E. P.; SILVA, L. M. M.; MARTINS, J. J. A.; GOMES, J. P.; ROCHA, A. P. T. Modelagem matemática para descrição da cinética de secagem de polpa de oiti. Revista Educação Agrícola Superior, v.26, n.2, p.108112, 2011.

SOUZA, R. L. A.; OLIVEIRA, L. S. C.; SILVA, F. L. H.; AMORIM, B. C. Caracterização da poligalacturonase produzida por fermentação semi-sólida utilizando-se resíduo de maracujá como substrato. Revista Brasileira de Engenharia Agrícola e Ambiental. v. 14, n. 9, p. 987-992, 2010.

VIANA, E. S. Embrapa realiza curso sobre processamento de frutas. Disponível em: <http://blog.cnpat.embrapa.br/índex. php?s=ipa>. Acesso em: 15/01/2018.

VINIEGRA-GONZALEZ, G. Solid state fermentation: definition, characteristics, limitation and monitoring, p. 5-22.
In: ROUSSOUS, S. et al. (Eds.) Advances in solid-state fermentation. Dordecht: Kluwer Academic Publishers, 1997. 